http://jmscr.igmpublication.org/home/

ISSN (e)-2347-176x ISSN (p) 2455-0450

crossref DOI: https://dx.doi.org/10.18535/jmscr/v7i7.29

\title{
The Existence of Autoscopic Hallucination ?- A Case Report and Review of Literature
}

\author{
Authors \\ Yogender kumar Malik ${ }^{1}$, Aseem Mehra ${ }^{2}$, Manoj Jangra ${ }^{3}$ \\ ${ }^{1}$ Senior Resident, ${ }^{2}$ Assistant Professor, ${ }^{3}$ Junior Resident \\ Department of Psychiatry, Post Graduate Institute of Medical Education and Research (PGIMER) \\ Chandigarh, 160012 \\ *Corresponding Author \\ Aseem Mehra \\ 3rd Floor, Cobalt Block, Nehru Hospital, PGIMER, Chandigarh, 160012, India
}

\begin{abstract}
Autoscopic hallucination has been the subject of interest in the literature for the past many years. The existence of the autoscopic hallucination in clinical practice has not been reported much. An autoscopic hallucination is a purely visual impression of seeing one's own body or its different parts as if being reflected in a mirror. Usually, this mirror image of oneself is naturally coloured. The image can be either motionless, or it imitates gestures or facial expressions. Mainly reported in organic conditionswith male predominance. However, it has been rarely reported in a psychiatric illness. We hereby report case of a female patient suffering fromschizophrenia who presented with unique phenomenology known as autoscopic hallucination.

Keywords: Autoscopic, hallucination, schizophrenia.
\end{abstract}

\section{Introduction}

Autoscopic hallucination is a rare psychopathology that has not been reported in the literature as much as have other kinds of psychopathology. Though it has been reported since ancient times yet not much attention was paid to it by theresearchers. Etymologically 'Autoscopy' is a word derived from the Greek words 'Autos' (self) and 'skopeo' (looking at). ${ }^{1}$ It is a kind of visual hallucination in which an individual is able to see, whole or a part of his/her body, in the external space, viewed from within his/her physical body. ${ }^{2}$ This phenomenon has been reported in association with organic pathologies like meningitis, seizures, space-occupying lesions, brain tumours, migraine, delirium, post-traumatic brain lesions. ${ }^{3,4}$ Two cases of autoscopic hallucinations are reported which were associated with alcohol and drug-induced respectively. ${ }^{5,6} \mathrm{~A}$ caseis reported in a young male who had schizophrenia with a history of substance use. ${ }^{7}$ All the cases were reported inmale subjects. The autoscopic hallucination is never reported in a female, suffering from primary psychiatric illness without having any comorbid physical illness or substance use. In the indexed case report,a case of youngfemale with schizophrenia who presented 
with rare phenomenon of autoscopic hallucination for the last five years.

\section{Case Report}

A 27 yearold unmarriedfemale belonging to an urban nuclear family of upper socio-economic status presented with symptoms of insidious onset, for last five years,characterised by auditory hallucinations: voices were discussing and commenting type. In additionto hearing voices she haddelusions of persecution and reference, maintainedpoor self-care, and had minimal social interaction. Over the course of time her condition deteriorated as she stopped going out of the home, would remain fearful and not participate in household chores. For these symptoms she was taken to various faith healers and local quacks without any apparent improvement. Forthe last two and half years, in addition to the above symptoms, she could be seen crying on and off for about 5-10 minutes about 3-4 times in a day. While crying, she would look fearful and point her fingers towards the wall. On being asked the reason for that she said that she would see herself, i.e. a photocopy of her, in front, about 2-3 feet away from her body. She would describe her double with the similar facial features, colour and style of hair, complexion, in fact, she would say "it is another me". She would say that her double would appear naked to her and was like her "mirror image" or "self". She would say that a man had come and raped the "self". She would have guilt that she could not save the "self"from being raped by someone. As per her "self" would ask for help in a loud volume and cry. At that time she denied having any sensations on her original body. She visited various psychiatrists, was started on antipsychotic but did not have much relief. Compliance was not so good, citing the reason of no improvement with the drugs. Apart from the above symptoms, she also had a significant decline in scholastic performance and stopped going to college. She would not attend social gatherings, would not participate in festivals too. She was brought to our outpatient clinic and diagnosed with schizophrenia. There was no remarkable family or history of psychiatric illness, sexual abuse or childhood emotional trauma. On mental status examination, the affect was fearful, she had auditory hallucinations discussing and commenting type, delusion of persecution, and impaired judgment with poor insight were present. There was no history of seizures, brain insult etc. She was conscious, cooperative and well oriented to time place and person. On Mini-mental state examination she scored 30/30. Her physical and Neurological examinations were unremarkable. Visual field was intact. All investigations including neuroimaging werewithin normal limit. Diagnosis of schizophrenia was made and started on Tab Risperidone up to $6 \mathrm{mg} / \mathrm{day}$. She improved about $70-80 \%$ over 5-6 months and was on regular follow up.

\section{Discussion}

Autoscopic hallucination has been known since ancient times. Being a rare phenomenon not much exact clinical description is available. It is the hallucinatory experience of perception of the self-body part/image projected into the real external space like a mirror image. ${ }^{1,2}$ The sufferer usually retains the insight into the unreality of the experience. In the patient with autoscopic hallucination, the image of the self is disliked by the person.Even Freud had a personal experience of this unique phenomenon and described it as the "The Uncanny". Freud stressed that distress arose from the "uncanny" effect of seeing one's self in the external space. $^{8}$ In 1953, another author defined it as a "delusional dissociation of the body image into the visual sphere". Lippman defined it as "hallucination of physical duality."There are two other phenomenons which are similar to the autoscopic hallucination,i.e. out of body experience and Heautoscopy. ${ }^{3}$ The unique character of autoscopic hallucination which differentiates it from others is the observer's perspective isclearly body centred, and the visual image of one's own bodyappears as a mirror 
reversal. ${ }^{9}$ The experience of "double" is also experienced in other disorders like Capgras syndrome. The main characteristics feature of the Capgras is the patient's delusional conviction that the "double" in his environment is not his "real self" but of some other person. ${ }^{10}$

As described in the introduction, autoscopic hallucination seems to follow a wide range of substance use as well as organic etiologies but neither of which can be positively ascribed to the index patient. ${ }^{3,4}$ The special feature of the index case is the occurrence of the autoscopic hallucination in a schizophrenic patient. According to our knowledge, the index case report is the first case of autoscopic hallucination reported in a female schizophrenic patient. The observed psychopathology is quite a rare reporting in clinical setting. The current discussion also emphasises that there is a need to spend more time and of a detailed questioning of a to explore such unique psychopathology.

\section{Reference}

1. Anzellotti F, Onofrj V, Maruotti V, Ricciardi L, Franciotti R et al. Autoscopic phenomena: Case report and review of literature. Behav Brain Funct 2011;7:2.

2. Dening TR, Berrios GE. Autoscopic phenomena. Br JPsychiatry1994;165:80817.

3. Blanke O, Mohr C. Out-of-body experience, heautoscopy, and autoscopic hallucination of neurological origin: Implications for neurocognitive mechanisms of corporeal awareness and self-consciousness, Brain ResReviews 2005;50: 184-99.

4. Devinsky O, Feldmann E, Burrowes K, Bromfield E.Autoscopic phenomena with seizures. Arch Neurol 1989;46:1080-88.
5. Joshi S, Thapa B, ShakyaR. Autoscopic Hallucination in Alcohol Dependence Syndrome: A Rare or Missed Phenomenon? Case Rep Psychiatry 2017; 1-3.

6. Aizenberg D, Modai I. Autoscopic and drug-induced Perceptual Disturbances. Psychopathology 1985;18:237-40.

7. Salama AEA. The Autoscopic Phenomenon: Case Report and Review of Literature. Can J Psychiatry 1981;26:47576.

8. Freud S. The "uncanny." The standard edition of the complete psychological works of Sigmund Freud, 1919; 17: 217256.

9. Brugger P. Reflective mirrors: Perspective-taking in autoscopic phenomena. Cogn Neuropsychiatry 2002; 7:179-94.

10. Berson RJ. Capgras' Syndrome. Am J Psychiatry 1983; 140(8): 969-978. 